\title{
Forests
}

\section{Gender, climate change and women's representation}

Houria Djoudia, Maria Brockhausaa, H. Carolyn Peach Brown ${ }^{b}$ and Solange Bandiaky-Badjic

\section{Key points}

- It is important to consider within-gender differences in needs and interests as between-gender differences. Family, tribe, class and age differences commonly override gender similarities.

- Men and women respond differently to climate change and variability. Within genders, other characteristics such as class, race, caste, culture, wealth, age and ethnicity influence responses and affect the impact of climate variability and change on livelihoods.

- Women's responses include coping in the short term, diversifying in the medium term and planning for the long term. In the short term this may heighten their vulnerability but in the long term their responses may help them gain more influence and power.

- The knowledge and insights that women could contribute to decisions on adapting to and mitigating climate variability and change are often neglected. This renders forest-dependent societies less adaptive.

- Women face many obstacles in making their voices heard and participating in making decisions on forest issues.

- Women are more likely to bring about policies and practices that address women's needs and priorities by advocating for women's interests and taking part in on-going policy processes than by focusing on gender equity in elected bodies or representation.

- Devising policies and processes to speed these changes in different situations will be complex and needs to draw on the needs, interests and knowledge of both men and women.

\section{Introduction}

The many millions who depend on forests for their livelihoods are likely to be both directly and indirectly affected by environmental, social and economic changes brought about by variability and changes in climate. Although there has been some progress, women are generally at a disadvantage in using, managing and marketing forest resources. Policies and decisions related to climate variability, climate mitigation and forest management in the face of climate change need to take gender issues into account.

\section{a CIFOR}

b University of Prince Edward Island

c UNDP-Africa Adaptation Program
This brief draws on papers that explore relationships between gender and climate variability and change in forest regions of Mali and Senegal (dry forests), and Congo Basin forest (humid forest) countries. The authors consider the different ways women and men respond to climate variability, and the different ways they are involved in policy processes and decisions related to climate change and forest management.

The studies make it clear that gender mainstreaming has yet to trickle down and become embedded in national and local government policies and practices relating to climate change and variability. Similarly, the local knowledge and interests of different groups of women forest users have yet to trickle up and influence decision making, policy and 
practice. While many documents related to climate change pay lip service to mainstreaming gender, they do not translate into equity on the ground. Equity itself does not necessarily mean equal treatment but rather arrangements that give women a voice and take into account their needs and interests.

\section{Gender, climate variability and change}

Men's and women's responses to climate variability and change differ. Men adopt tactics such as migrating in the short term and relying on political solutions in the longer term. Women tend to adapt in the short term, diversify in the medium term and plan for the long term. In the short term women's strategies may heighten their vulnerability but in the long term their strategies may bring sustainable benefits, and give them more influence and power.

In northern Mali where Lake Faguibine is drying out and forests are replacing seasonally flooded cropland and pasture, Djoudi and Brockhaus (2011) find that men often adapt by migrating. The women left behind cope with a bigger workload, taking on activities such as herding livestock, previously done by men. Development projects in this area did not plan for changes in water availability as Lake Faguibine dried out. Instead, projects aimed to improve existing systems which were dependent on water. Climate variability and the likely effects of climate change were not taken into account.

As well as taking on work previously done by men, women in the Lake Faguibine area respond to changing circumstances by diversifying and venturing into traditionally male activities. Women started making charcoal as trees colonised the dried out lake bed.

Men, as well as migrating in the short term, are more aware of local politics and bank on longer term plans to re-flood the lake proposed by politicians. Women put the education of their children as a high priority. Education will open opportunities for offspring to take jobs that are not based on natural resources. This will lessen the impact of climate variability and change on households.

\section{Barriers to adapting and diversifying}

In coping in the short term women often have little choice. Education of children conflicts with their immediate need for help with farming, gathering or herding to keep the family fed and healthy. In diversifying, women are often hampered by tenure arrangements that limit their access to forests. Around Lake Faguibine, for example, the distribution of permits to make charcoal is determined by male-dominated power and personal networks. These limit women's right to wood and mean that their charcoal production is 'illegal'. Women face further barriers in marketing what they produce. Distance from the home and cultural conventions mean it is often not easy for women to go to market. Social and political networks of producers and sellers of charcoal habitually exclude women.

Adding to this complexity are differences between women of different class, race, caste, culture, wealth, age and ethnicity. Opportunities to cope, adapt and diversify vary between groups and influence the kinds of actions they can take and the roles they can play. For example, in the hierarchy in northern Mali, it is only women in 'lower class' Iklan households who can acceptably venture into making charcoal.

Services that would help women cope, diversify and plan for climate variability and change favour men. In Senegal, for example, cooperatives put men first when distributing seeds and fertilisers, and introducing new farming technologies. In general, women are also usually less educated than men and rely on men to deal with forms and bureaucracy. Yet a further barrier can be the tendency for donors to push women into 'women's groups' rather than integrate them into existing systems.

New measures to reduce deforestation may also erect barriers for women. Countries stand to benefit from policies on REDD+ (Reducing Emissions from Deforestation and Forest Degradation in developing countries, and the role of conservation, sustainable management of forests, and enhancement of forest carbon stocks in developing countries) that mitigate climate change by maintaining and restoring forest carbon sinks. However, because of insecure rights to land, forest and tree resources, discrimination and a bias towards providing services to males rather than females (Gurung and Quesada 2009, Bandiaky-Badji and Tiani 2010, Mwangi et al. 2011) REDD+ may undermine women's capacity to adapt to climate change (The World Bank et al. 2009, Demetriades and Esplen 2010). 


\section{Gender and representation in REDD+}

To date, women have not been involved to any significant extent in discussions on climate change and REDD+ although there is some evidence that gender issues will be integrated in future national REDD+ strategies.

Peach Brown (2011) examined whether gender considerations are part of discussions and influence decisions on climate change in three Congo Basin forest countries: Cameroon, the Central African Republic and the Democratic Republic of Congo. Documents concerning adaptation, National Adaptation Program of Action (NAPA) plans, mitigation, and REDD+, state the need, often dictated by donors, for a gender-sensitive approach to adapting to climate change. However, women and government departments mandated to address gender issues in Congo Basin forest countries did not participate to any significant extent in the development of these papers. The initial documents drawn up for REDD+ did not address gender (Table 1).

Subsequent documents do use gender- sensitive language and speak to gender issues but the most recent documents may be more of a 'technical fix' than a reflection of reality. Nevertheless, the use of gender language and inclusion of gender issues, although in vague terms, are a start and provide a handle for holding authorities accountable for gender equity in future negotiations (Hemmati and Röhr 2009).

More women need to be involved in consultations and planning for REDD+. More involvement by itself may not transform into more influence on agendas and integration of women's interests. Being involved is not equivalent to having a voice or being able to influence outcomes (Cornwall 2008). Neither does better, fairer and more responsive governance of forests necessarily follow. Here factors such as power, social and cultural norms and knowledge come into play (Biermann et al. 2009).

\section{Equity and climate change strategy}

Tapping into the different kinds of knowledge held by men and women strengthens national adaptation and mitigation strategies. For example, studies show that involving more women in forest governance leads to better resource conservation and regeneration (Agarwal 2009). Involvement of both men and women exploits the particular strengths of each and tempers their shortcomings (Mwangi et al. 2011). Nevertheless, addressing gender inequity is complex, requiring changes in entrenched power and cultural norms biased against women. Forests are important to the livelihoods of women. Their marginalisation from decisionmaking and policy processes on climate change and forests means it is important to understand how to include them and make sure their interests are addressed.

\section{Equity and local representation}

International and national policies to mitigate and adapt to climate change translate into action at the local level. In determining appropriate action, it is as important to consider within-gender differences in needs and interests as between gender differences. Family, tribal, class and age differences commonly override gender similarities.

Table 1. Gender consideration in policy forums and processes in three Congo Basin forest countries

\begin{tabular}{llll}
\hline Policy forum or process & Democratic Republic of Congo & Central African Republic & Cameroon \\
\hline $\begin{array}{l}\text { National Adaptation Program } \\
\text { of Action }\end{array}$ & $\begin{array}{l}\text { Gender consideration included } \\
\text { Readiness Planning Idea Note }\end{array}$ & $\begin{array}{l}\text { Gender consideration included } \\
\text { concerns }\end{array}$ & Not applicable \\
$\begin{array}{l}\text { Readiness Preparation Plan or } \\
\text { Proposal }\end{array}$ & $\begin{array}{l}\text { Gender consideration included } \\
\text { REDD+ workshops }\end{array}$ & $\begin{array}{l}\text { Gencerns } \\
\text { cender consideration included }\end{array}$ & $\begin{array}{l}\text { No evidence of gender } \\
\text { concerns }\end{array}$ \\
$\begin{array}{l}\text { National committee } \\
\text { 'Gender' departments }\end{array}$ & $\begin{array}{l}\text { No evidence of gender } \\
\text { concerns } \\
\text { Not included in climate change } \\
\text { or REDD+ processes }\end{array}$ & $\begin{array}{l}\text { Not included in climate change } \\
\text { or REDD+ processes }\end{array}$ & Not applicable \\
\hline
\end{tabular}


Women are not a homogenous group. Local customs, social
networks and influence uphold inequity as much as formal laws. Information and communication campaigns, meetings, financing, training and capacity building can help local institutions move towards equity in the long term.

\section{Gender and forest management}

The ratio of men to women in user groups influences access to forests, how they are managed and the ways forests are used. Men more often harvest timber or grow cash crops such as coffee and cocoa, whereas women grow and gather food, fuel and fodder (Agarwal 2000, Bolanos and Schmink 2005). When it comes to forest management, the most important roles for women are often considered to be in protecting the environment. Women's needs, the constraints they face in accessing forest resources, or the impacts of changes in forest ecosystems as a result of climate variability on women's lives are repeatedly neglected.

\section{Lack of recognition of the roles women play}

Even though the law in Senegal gives women access to land, in fact this is still dependent on local norms which favour men (IED 2006). Senegalese documents such as the 1981 Forest Development Action Plan, the 1984 Desertification Report and 1992 Forestry Plan do not acknowledge women's role in alleviating desertification or the impact of desertification on women's lives.

The Earth Summit in 1992 and Agenda 21 steered international and national policies towards participatory, decentralised land and forest resources management by local elected officials. Forest governance in Senegal, as in many countries, follows these international conventions and donor agendas that mainstream local governance and gender in order to secure funding.

\section{Theory and practice}

The result in Senegal is that in theory management of forest resources is decentralised but, in practice, it is still centrally managed. The state owns forest resources and assigns local councils or 'collectivitiés' to allocate and manage them. The complex tenure regime-a mix of customs, statutes and local government-has a poor track record of serving women's interests. Both customary and formal laws largely ignore the rights and access of women to forest resources.

\section{Culture and politics}

Patronage, the structure and organisation of political parties, and cultural attitudes bar women from seeking and gaining political office. In Senegal, for example, very few women hold elected office although they participate en masse in electoral politics. Laws and policies relating to access to and ownership of land and forest resources in Senegal are gender neutral or gender blind. Nevertheless, maledominated national and local government institutions and official processes systematically under-represent or exclude women from land and forest governance.

When issues of gender, power and difference are ignored, existing inequalities, exclusions or antipathies are often perpetuated (Lennie 1999). Combinations of culture, politics and economics determine men's and women's participation in making decisions and shaping practices. Poor or lack of women's representation on rural councils hinders women's access to land and forestry resources. Decentralisation in Senegal in the 1990s exacerbated such a situation. The new structures did not give women more power. In many cases responsibilities merely devolved to male-dominated local councils. Men still control access to forest resources and women have little say.

\section{Opportunities for addressing gender equity}

By effectively participating in existing mechanisms and reform processes women can hold both male and female politicians, and local and national government officials, accountable for failing to recognise and implement women's rights to forest and land resources. Advocacy and influencing can help bring about clear, national forest laws and policies that take women's needs and interests into account.

\section{Existing frameworks}

Decentralisation in Senegal in itself has not given women equal participation or representation in forest governance, or equal access to forest resources. Decentralisation does however offer an opportunity to address inequities because it is the legal framework for forest governance and applies to all stakeholders and forest users. 


\section{Equity laws}

Laws stipulating equal representation by men and women, such as the 2010 Senegalese law, are further opportunities to address inequities. Equal representation in some cases provides the critical mass to bring about change. With equal representation women have an opportunity to show they can be accountable-by answering for how they establish what any group of women wants or thinks, how they represent women's needs and how they translate women's needs and interests into policies and political agendas in both local and national spheres.

\section{Reform processes}

As well as equal political representation, advocacy and participation in reform processes are avenues for securing gender equity. Although women may not yet have equal power or control, by organising themselves effectively they can boost their bargaining power and influence policy processes.

\section{Conclusions}

The studies in sub-Saharan African forest regions reinforce previous findings. Gender influences women's and men's roles in managing forests, their access to forests and how they use forest resources. Climate variability is likely to shift roles, rights and uses between genders. Access to and ownership of forest resources governs women's livelihoods in forest-dependent communities but governance and politics do not reflect this.

Significantly, the studies make clear that across-the-board simplifications are dangerous. Power, influence and attitudes vary between different groups of women and over time. Policies and practices to sustainably manage, conserve and develop all types of forests under variable climate regimes need to consider complex gender and withingender relationships.

Gender equity should contribute to good governance: fair, equitable and representative structures, processes and practices. This means enforcing laws and making those responsible accountable. Women must simultaneously continue to address entrenched political, social and cultural norms biased against them and pursue accountability.
Although in the short term climate variability and change may make women more vulnerable, in the long term changes in social, political and economic norms may lessen their vulnerability. As they make their voices heard they are more likely to succeed in achieving more equitable and secure access to land, natural resources and markets. Devising policies and processes to speed these changes in different situations will be complex and needs to draw on the needs, interests and knowledge of both men and women.

\section{References}

Agarwal, B. 2000 Conceptualizing environmental collective action: why gender matters. Cambridge Journal of Economics 24: 83-310.

Agarwal, B. 2009 Gender and forest conservation: the impact of women's participation in community forest governance. Ecological Economics 68: 2785-2799.

Bandiaky-Badji, S. 2011 Gender equity in Senegal's forest governance history: why policy and representation matter. International Forestry Review 13(2): 177-194.

Bandiaky, S. and Tiani, A-M. 2010 Gender representation and participation in decentralized forest management: case studies from Cameroon and Senegal. Governing Africa's Forests in a Globalized World. L.A. German, A. Karsenty and A.M. Tiani. London, Earthscan: 144-159.

Biermann, F., Betshill, M.M., Gupta, J., Kanie, N., Lebel, L., Liverman, D., Schroeder, H. and Siebenhuner, B. 2009 Earth system governance: people, places and the planet. Earth System Governance Project Report No. 1. Bonn International Human Dimensions Programme on Global Environmental Change: 148.

Bolanos, O. and Schmink, M. 2005 Women's place is not in the forest. Gender issues in a timber management project in Bolivia. In: Colfer, C.J.P (ed.): The equitable forest: diversity and community in sustainable resource management. Resources for the Future and CIFOR Publication, Washington D.C. 274-295.

Cornwall, A. 2008 Unpacking 'participation' models, meanings and practices. Community Development Journal 43(3): 269-283.

Demetriades, J. and Esplen, E. 2008 The gender dimensions of poverty and climate change adaptation. IDS Bulletin 39(4): 24-31.

Djoudi, H. and Brockhaus, M. 2011 Is adaptation to climate change gender neutral? Lessons from communities dependent on livestock and forests in northern Mali. International Forestry Review 13(2): 123-135. 
Gurung, J.D. and Quesada, A. 2009 Gender differentiated impacts of REDD to be addressed in REDD social standards. Women Organizing for Change in Agriculture and Natural Resource Management and Global Gender and Climate Alliance: 13.

Hemmati, M. and Röhr, U. 2009 Engendering the climatechange negotiation: experiences, challenges and steps forward. Gender and Development 17(1): 19-22.

IED (Institut International pour l'Environnement et le Développement), 2006 Aspects juridique lies au genre et à la décentralisation au Sénégal. Une contribution au projet de réforme de l'administration locale. Etude réalisée par Moustapha Ngaïndé en collaboration avec Rokhaya Chambaz, Programme Réussir la Décentralisation.
Lennie, J. 1999 Deconstructing gender power relations in participatory planning: toward an empowering feminist framework of participation and action. Women's Studies International Forum 22(1): 99-112.

Mwangi, E., Meinzen-Dick, R. and Sun, Y. 2011 Gender and sustainable forest management in East Africa and Latin America. Ecology and Society 16(1): 17.

Peach Brown, H.C. 2011 Gender, climate change and REDD+ in the Congo Basin forests of Central Africa. International Forestry Review 13(2): 163-176.

The World Bank, Food and Agriculture Organization of the United Nations (FAO) and International Fund for Agricultural Development (IFAD), 2009 Gender in Agriculture Sourcebook. Washington D.C. The World Bank.

This work was undertaken with financial assistance from the European Union under the project 'Tropical Forests and Climate Change Adaptation' (TroFCCA) executed by Centro Agronómico Tropical de Investigación y Enseñanza (CATIE, Costa Rica) and CIFOR and funded by the European Commission under contract EuropeAid/ENV/2004-81719. Research in the Congo Basin was conducted under the International Development Research Centre (IDRC) funded Congo Basin Forest Climate Change Adaptation project of CIFOR and a Social Sciences and Humanities Research Council of Canada Postdoctoral Fellowship. The research was also supported by the Global Environmental Change Group in the Department of Geography at the University of Guelph.

This brief is based on three papers:

Bandiaky-Badji, S. 2011 Gender equity in Senegal's forest governance history: why policy and representation matter. International Forestry Review 13(2): 177-194.

Djoudi, H. and Brockhaus, M. 2011 Is adaptation to climate change gender neutral? Lessons from communities dependent on livestock and forests in northern Mali. International Forestry Review 13(2): 123-135.

Peach Brown, H.C. 2011 Gender, climate change and REDD+ in the Congo Basin forests of Central Africa. International Forestry Review 13(2): 163-176.

\section{Center for International Forestry Research}

CIFOR advances human wellbeing, environmental conservation and equity by conducting research to inform policies and practices that affect forests in developing countries. CIFOR is one of 15 centres within the Consultative Group on International Agricultural Research (CGIAR). CIFOR's headquarters are in Bogor, Indonesia. It also has offices in Asia, 